\title{
Monitoring diaphragm function in the ICU
}

\author{
Martin Dres, MD, PhD, Alexandre Demoule, $\mathrm{MD}, \mathrm{PhD}$
}

${ }^{1}$ Sorbonne Université, INSERM, UMRS1158 Neurophysiologie respiratoire expérimentale et clinique, Paris, France

2 AP-HP, Groupe Hospitalier Pitié-Salpêtrière Charles Foix, Service de Pneumologie, Médecine intensive - Réanimation (Département "R3S"), F-75013, Paris, France

\section{Correspondence:}

Dr Martin Dres

Service de Pneumologie, Médecine intensive - Réanimation

Groupe Hospitalier Pitié-Salpêtrière

47-83 boulevard de 1'Hôpital

75651 Paris Cedex 13, France

Phone: 331421677 61; Fax: 33170247282

E-mail: martin.dres@aphp.fr

\section{Acknowledgment}

Damien Bachasson (Institut de Myologie) for his kind help in preparation of the Figures.

\section{Financial support and sponsorship}

None

\section{Conflicts of interest}

Martin Dres received personal fees for expertise from Lungpacer.

Alexandre Demoule reports personal fees from Medtronic, grants, personal fees and nonfinancial support from Philips, personal fees from Baxter, personal fees from Hamilton, personal fees and non-financial support from Fisher \& Paykel, grants from the French Ministry of Health, personal fees from Getinge, grants and personal fees from Respinor, grants and non-financial support from Lungpacer. 


\section{Purpose of review}

This article reviews the clinical problem of diaphragm function in critically ill patients and describes recent advances in bedside monitoring of diaphragm function.

\section{Recent findings}

Diaphragm weakness, a consequence of diaphragm dysfunction and atrophy, is a common condition in the intensive care unit and is associated with serious clinical consequences. Bedside diaphragm function monitoring can now be performed by means of two approaches: diaphragm electrical activity and diaphragm ultrasound. The use of ultrasound to assess diaphragm structure (thickness, thickening) and mobility (caudal displacement) appears to be feasible and reproducible, but no large-scale "real-life" study is available. Diaphragm ultrasound can also be used to evaluate diaphragm muscle stiffness by means of shear wave elastography and strain by means of speckle tracking, both of which are correlated with diaphragm function in healthy subjects. Electrical activity of the diaphragm is correlated with diaphragm function during brief airway occlusion, but the repeatability of these measurements exhibits high within-subject variability.

\section{Summary}

Mechanical ventilation is involved in the pathogenesis of diaphragm dysfunction, which is associated with severe adverse events. Although the use of ultrasound and diaphragm electrical activity recording could potentially facilitate monitoring of diaphragm function in order to deliver diaphragm-protective ventilation, no guidelines concerning the use of these modalities have yet been published. The weaning process, assessment of patient-ventilator synchrony and evaluation of diaphragm function may be the most clinically relevant indications for these techniques.

\section{Keywords}

Diaphragm, electrical activity, thickening fraction, excursion, mechanical ventilation. 


\section{Introduction}

Careful and safe use of mechanical ventilation is a major issue in the intensive care unit (ICU). Mechanical ventilation certainly helps patients to overcome the most severe forms of acute respiratory failure, but, in the meantime, also produces unintended harmful effects. One such harmful effect, diaphragm atrophy and dysfunction resulting from ventilatorinduced respiratory muscle disuse, has become an issue of major concern. Diaphragm atrophy and dysfunction are commonly observed in mechanically ventilated patients (1-3) and are associated with difficult and prolonged weaning (3), prolonged duration of mechanical ventilation (3), ventilator-associated complications (re-intubation, tracheostomy) (2) and mortality (3). However, significant technological and physiological progress has been made, allowing bedside monitoring of diaphragm function. Like all muscles, the diaphragm contracts, shortens, thickens, stiffens and finally generates a pressure inside the thorax that allows alveolar ventilation, the ultimate goal of breathing. Diaphragm function can now be evaluated at the bedside by means of several approaches (4). Transmission of respiratory drive can be recorded by monitoring the electrical activity of the diaphragm (EAdi). It is also possible to directly visualize by the thickening of the diaphragm by ultrasound and more recently, it has been reported that diaphragm ultrasound can be used to evaluate diaphragm stiffness and deformation (strain). Of note, the reference technique to investigate diaphragm function is phrenic nerve magnetic stimulation, but it can only be performed in expert centres, which explains the growing interest in diaphragm ultrasound and EAdi recording as potential bedside substitutes. In the present review, we will discuss recent evidence highlighting the clinical issues related to diaphragm dysfunction in the ICU and the potential importance of diaphragm function monitoring. Finally, the latest developments on diaphragm function monitoring will be described before discussing translation of recent knowledge into clinical practice. 


\section{Why diaphragm function monitoring is important in the ICU?}

\section{Diaphragm dysfunction is a common condition}

A landmark study published by Levine et al. demonstrated rapid disuse-induced atrophy of diaphragm fibers in brain-dead adult donors exposed to several hours of mechanical ventilation (5). This observation is consistent with a core of animal studies and more recent ultrasound-based analysis demonstrating the impact of ventilator-induced diaphragm disuse on diaphragm atrophy (6) and dysfunction. ICU patients are exposed to several other risk factors of diaphragm dysfunction in addition to mechanical ventilationinduced disuse (i.e. sepsis, critical illness severity) making it difficult to determine the specific contribution of mechanical ventilation to the development of diaphragm dysfunction (7). Regardless of the risk factors involved, various studies have reported a high prevalence of diaphragm dysfunction in the ICU, as more than two-thirds of mechanically ventilated patients are diagnosed with diaphragm dysfunction at the time of the first weaning attempt (7).

\section{Diaphragm dysfunction is a major concern}

Diaphragm dysfunction has major implications for ICU patients. Firstly, as the diaphragm is a major determinant of the load/capacity respiratory balance, diaphragm dysfunction may increase the risk of weaning failure and subsequently prolong the duration of mechanical ventilation. Importantly, a recent study has suggested that diaphragm function is predominantly a key determinant for the outcome of the spontaneous breathing trial rather than the outcome of extubation. Secondly, diaphragm dysfunction has been associated with complications such as reintubation, tracheostomy and prolonged ventilation (2), and postoperative complications $(8,9)$. It is also associated with ICU mortality (7).

\section{Diaphragm-ventilator interaction}


Under certain circumstances, patients may struggle against the ventilator, which generates asynchrony. In turn, asynchrony may be associated with discomfort, dyspnea and poor prognosis. However, detection of asynchrony is not an easy task for clinicians. While visual inspection of airway pressure, volume and flow waveforms allows the detection of gross asynchronies, this method is not sufficiently reliable and sensitive. The reference method is based on the use of an esophageal catheter to visualize mismatches between changes in pleural pressure and changes in airway pressure and flow waveforms. Diaphragm contraction plays a crucial role in changes in pleural pressure, suggesting that monitoring diaphragm function simultaneously with the breathing pattern could facilitate the detection of patient-ventilator asynchrony (10).

\section{What is diaphragm function and how can it be monitored in the ICU?}

The diaphragm is a musculotendinous structure stretched between the thorax and the abdomen, making direct examination impossible (Figure 1). Bedside investigation of diaphragm function requires costly equipment and involves semi-invasive approaches. For these reasons, apart from research purposes, diaphragm function monitoring has rarely been performed in clinical practice in recent years. However, things have changed with the emergence of techniques such as diaphragm ultrasound and recording of the electrical activity of the diaphragm by means of a dedicated esophageal catheter. Before describing these techniques, we will discuss the definition of diaphragm function and the reference method used to diagnose diaphragm dysfunction.

\section{Pressure-generating capacity}

The physiological function of the diaphragm is to shorten and produce a force. Although this force cannot be measured directly, the capacity of the diaphragm to generate a pressure can be measured. When the diaphragm contracts, it descends towards the abdomen, 
which simultaneously generates increased abdominal pressure and decreased thoracic pressure, resulting in a transdiaphragmatic pressure (Pdi). The maximum Pdi, which is the Pdi generated by a forced inspiratory effort, is considered to be the most physiological approach to assessment of diaphragm function. However, ICU patients are generally unable to produce maximum effort due to lack of cooperation induced by sedation or delirium. To overcome this issue, it has been proposed to measure Pdi in response to supramaximal bilateral magnetic phrenic nerve stimulation (Pdi,twitch). While Pdi in response to magnetic stimulation is not a substitute for maximum Pdi, it has the advantage of being independent of the patient's cooperation and is able to provide standardized measurements. As measuring transdiaphragmatic pressure requires both esophageal and gastric balloons, it is acceptable to exclusively use changes in tracheal pressure during magnetic phrenic nerve stimulation (Ptr,stim) to evaluate diaphragm function. A Ptr,stim less than $-11 \mathrm{cmH}_{2} \mathrm{O}$ is used to define diaphragm dysfunction in the ICU (Table 1).

\section{Diaphragm ultrasound}

Over the last 10 years, diaphragm ultrasound has been increasingly used in the ICU and several studies have been published on this topic in adults (11) and children (12-14). When the diaphragm contracts, it shortens, thickens, displaces and stiffens. Ultrasound can measure diaphragm thickness, thickening and displacement (also called excursion) (Figure 1). For reasons of feasibility, diaphragm ultrasound is mainly performed on the right hemidiaphragm via two approaches: subcostal and intercostal (Figure 2). The subcostal approach visualizes caudal displacement of the hemi-diaphragm. Measurement of the excursion of the right hemi-diaphragm is associated with high intra- and inter-observer reliability (15). The lower limit of normal is greater than $3.6 \mathrm{~cm}$ in women and greater than $4.7 \mathrm{~cm}$ in men during maximum inspiratory effort (15). In healthy subjects, there is a moderate correlation between diaphragm excursion and markers of pressure-generating capacity (16). In mechanically 
ventilated patients, diaphragm excursion is poorly correlated with markers of pressuregenerating capacity (pressure-time product of transdiaphragmatic pressure, transdiaphragmatic pressure, twitch pressure), but has been associated with weaning outcome (the greater the excursion, the better the outcome) (17). In contrast, diaphragm thickness is not correlated with either markers of pressure-generating capacity or weaning outcome (17). Diaphragm ultrasound can detect a decrease in diaphragm thickness, suggesting diaphragm atrophy (2), but increased thickness has also been reported (2) although the significance of this observation remains unclear. A remarkable observation on the relationship between histological diaphragm atrophy and pulmonary function tests was recently reported in patients with amyotrophic lateral sclerosis (18). The authors failed to demonstrate any significant correlation between markers of pressure-generating capacity and severity of diaphragm atrophy (18). These findings suggest that atrophy is only one of several markers of diaphragm dysfunction.

Changes in thickness between expiration and inspiration can be used to determine the diaphragm thickening fraction, defined as the difference between end-inspiratory and endexpiratory diaphragm thickness over the end-expiratory diaphragm thickness, expressed as a percentage. Measurement of diaphragm thickening fraction is less reproducible than measurement of diaphragm thickness (19). There is a poor correlation between diaphragm thickening fraction and diaphragm function (17) because thickening is a one-dimensional parameter, whereas diaphragm contraction results from active three-dimensional displacement of muscle volume (4). The correlation between diaphragm thickening fraction and markers of pressure-generating capacity is therefore only moderate, ranging from $r^{2}=0.28$ in healthy subjects (19) to rho=0.87 in mechanically ventilated patients (20). This wide range indicates a limited validity of diaphragm thickening fraction to quantify diaphragm effort. Of note, the validity of TFdi to estimate diaphragm effort has been recently questioned in a study in which 
TFdi remained unchanged in healthy subjects exposed to a stepwise threshold inspiratory loading protocol from 0 to $50 \%$ of maximum inspiratory pressure (21). However, the poor intra-operator reproducibility coefficient $(85 \%)$ in this study could explained the lack of change in TFdi during the protocol. In the ICU, diaphragm thickening fraction (and diaphragm excursion) should be measured, whenever possible, with the lowest ventilatory assistance and ideally under continuous positive airway pressure set to zero or via a T-tube to avoid underestimation of diaphragm thickening fraction and excursion. A cut-off $<29 \%$ for diaphragm thickening fraction has been associated with diaphragm dysfunction in mechanically ventilated patients (20) and cut-off values for predicting successful weaning (success of the spontaneous breathing trial and/or extubation success) range between $25 \%$ and $35 \%(17,22-24)$. A study comparing diaphragm ultrasound and phrenic nerve stimulation showed that both methods accurately predicted weaning outcome (22). However, discordant results have been reported for the performance of diaphragm thickening fraction to predict weaning outcome. One study reported that diaphragm thickening fraction measured before starting the weaning trial was significantly higher in patients who failed the weaning trial compared to patients who had passed the weaning trial with no other between-group differences until the end of the trial (25). The maximum diaphragm thickening fraction and maximum excursion were also similar in both groups before starting the weaning trial (25). In contrast, other authors have observed a lower diaphragm thickening fraction in patients who subsequently failed the weaning trial (17). Another study that enrolled patients who had successfully passed the weaning trial reported no difference in terms of diaphragm thickening fraction or diaphragm excursion between patients successfully extubated and those who failed extubation (26). Altogether, these findings emphasize the importance of standardizing the use of diaphragm ultrasound during weaning. Such standardization could take into account the timing of the measurement (before or during the weaning trial), the patient population of 
interest (those at highest risk of weaning failure), the conditions of ventilation (unassisted ventilation may be preferred) and the measurements (tidal or during maximum effort depending on the level of patient cooperation). Some authors have suggested combining an ultrasound-derived index with the breathing pattern $(27,28)$. Spadaro et al. observed that the ratio of diaphragm excursion over respiratory rate performed better than the rapid shallow breathing index, diaphragm excursion alone and maximum inspiratory pressure to predict weaning outcome (27). Other authors have sought to evaluate the performance of changes in the excursion-time index (a product of diaphragm excursion and inspiratory time) between assist-control mode and spontaneous breathing trial to predict extubation outcome (28). In this study, a decrease in excursion-time index less than $3.8 \%$ between assist-control mode and spontaneous breathing trial had a sensitivity of $79.2 \%$ and a specificity of $75 \%$ to predict successful extubation (28).

In another study, diaphragm ultrasound was used to identify patients presenting to the emergency room with acute exacerbation of chronic obstructive pulmonary disease to predict the risk of non-invasive ventilation failure (29). Patients with diaphragm dysfunction, defined by a diaphragm thickening fraction $<20 \%$ on tidal ventilation, were found to be more likely to fail noninvasive ventilation (risk ratio $=4.4 ; \mathrm{p}<0.001)(29)$.

Apart from classical ultrasound-derived indices, longitudinal shortening of the diaphragm (strain) can also be measured by speckle tracking (21) and diaphragm stiffness can be measured by shear wave elastography (Figure 3) (30). A moderate to strong correlation between strain and isometric contractions has been demonstrated in skeletal muscles (31). Preliminary findings indicate a strong correlation between strain and transdiaphragmatic pressure $\left(\mathrm{r}^{2}=0.72(\mathrm{P}<0.0001)(21)\right.$. Shear wave elastography is an ultrasound-based imaging technique that noninvasively measures shear wave velocity propagating in a target tissue and shear wave velocity is directly correlated with stiffness index (shear modulus) (32). 
Because of the strong linear relationship between muscle shear modulus and active muscle force, ultrasound shear wave elastography provides an index of change of individual muscle force. A strong correlation $\left(r^{2}>0.95\right)$ between submaximal inspiratory mouth pressure and diaphragm shear modulus is observed in healthy subjects (30) and a strong correlation is observed between transdiaphragmatic pressure and shear modulus during isovolumetric inspiratory effort against closed airways $(r=0.82)$ and during ventilation $(r=0.70)$ against inspiratory loading (32). Diaphragm strain and diaphragm shear modulus may be able to provide complementary data in the evaluation of diaphragm function but no study in ICU patients has yet been published.

\section{Diaphragm electrical activity}

Diaphragm electrical activity can be measured by surface electromyography (EMG) or multi-array esophageal electrodes. The main advantage of monitoring diaphragm function by surface EMG is that it is continuous and noninvasive, but it is frequently contaminated by the electrocardiogram or neighboring muscle activity and it is subject to power and electromagnetic interferences. Multi-array esophageal electrodes can facilitate recording of the electrical activity of the diaphragm by using a dedicated nasogastric feeding tube, allowing continuous monitoring of EAdi. However, EAdi values are difficult to interpret, as only very limited data concerning "normal" values are currently available. A recent study reported a broad range of median EAdi peaks in spontaneously breathing healthy subjects (from $5 \mu \mathrm{V}$ to $30 \mu \mathrm{V}$ ), but usually around $15 \mu \mathrm{V}$ (33). Interestingly, surface EMG of the diaphragm correlates very well with EAdi after averaging breaths into deciles (34). EAdi can be interpreted together with the breathing pattern in order to evaluate the transformation of drive (EAdi) into pressure or tidal volume (VT) (neuromechanical coupling). A strong correlation has been reported between EAdi and transdiaphragmatic pressure (Pdi), notably during end-expiratory occlusion, suggesting that the neuromechanical efficiency ratio 
( $\Delta \mathrm{Pdi} / \Delta \mathrm{EAdi})$ could be useful to estimate inspiratory effort on breath-by-breath analysis (35). Similar findings have also been recently reported in children (36). However, the repeatability of the measurements of the neuromechanical efficiency ratio recently has been questioned, as these measurements currently exhibit marked within-subject variability (37). This poor repeatability could potentially constitute a major limitation and clinicians must use several measurements to select occlusions with the lowest variability in order to estimate inspiratory muscle effort from EAdi (37). The transformation of EAdi into VT can also be studied by calculating the neuroventilatory efficiency index (VT/EAdi). The VT/EAdi ratio can allow early distinction between patients likely to pass or fail the spontaneous breathing trial (38). Lastly, the patient-ventilator breath contribution (PVBC) index can be used to determine the respective contribution of the patient and the ventilator to total inspiratory VT. This index is calculated as the ratio of inspiratory VT/EAdi during unassisted breaths (no pressure support) over the same ratio during assisted breaths (with pressure support). A higher PVBC index indicates a higher contribution of the patient. Once again, poor reliability has been reported for measurements of the PVBC index using the currently available methods (39). However, after using a new algorithm for EAdi matching between assisted and unassisted breaths (in order to select assisted and unassisted breaths displaying similar EAdi), the authors significantly improved the reliability of the measurements (39).

\section{What are the indications for diaphragm function monitoring?}

Taking into account both the effects of excessive ventilatory assistance on the risk of diaphragm dysfunction and the effects of insufficient ventilatory assistance on the risk of patient self-inflicted lung injury (40), the main objective of diaphragm function monitoring would be to closely tailor the appropriate level of assistance to the patient's needs and comfort. Some strategies designed to protect the lungs and mitigate the effects of diaphragm 
disuse have been proposed, but they now need to be tested before they can be generalized (41). In particular, ultrasound may be useful to monitor diaphragm function together with airway or esophageal pressure recordings to assess patient-ventilator asynchrony (10). A possible application of diaphragm ultrasound in this context could be monitoring of patients with acute respiratory distress syndrome treated by deep sedation or neuromuscular blocking agents to ensure that they do not exhibit hidden asynchronies. However, in order to be clinically relevant, this type of monitoring would need to be displayed continuously, which would require further technological improvements before it can be used in a clinical decision support system (42). Another application of diaphragm monitoring would be the weaning from mechanical ventilation (17). Diaphragm monitoring could be particularly useful in patients presenting difficult and prolonged weaning and could help to diagnose diaphragm dysfunction that can interfere with the weaning process, but it could also be used as a predictor of extubation failure in order to implement appropriate preventive strategies. Lastly, diaphragm function monitoring could be used to evaluate inspiratory effort in order to titrate the level of ventilator assistance in patients requiring prolonged weaning. Normal ranges of inspiratory effort would need to be available before this technique could be used in routine clinical practice. 


\section{Conclusion}

Monitoring diaphragm function in the ICU could help physicians to more clearly understand the interaction between the patient's effort and the ventilator. It could participate in the ventilator setting decision-making process. Ultimately, diaphragm function monitoring could be very useful in patients with difficult and prolonged weaning by predicting weaning failure and diagnosing diaphragm dysfunction. Future research into diaphragm monitoring in the ICU must investigate the correlation (and its determinants) between standard markers of diaphragm function and ultrasound-derived indices and electrical activity. The reproducibility of clinical measurements must also be improved. Standardization in the form of specific good practice guidelines for diaphragm ultrasound and electrical activity recording in mechanically ventilated patients is also necessary.

\section{Key bullet points}

- Diaphragm dysfunction is common in the ICU and is associated with prolonged duration of mechanical and respiratory complications.

- Diaphragm ultrasound and diaphragm electrical activity recording are useful to monitor the diaphragm function at the bedside.

- Diaphragm monitoring may be used to tailor the ventilator settings in order to provide a diaphragm protective ventilation - between over and under diaphragm use. 


\section{References}

1. Vivier E, Roussey A, Doroszewski F, Rosselli S, Pommier C, Carteaux G, et al. Atrophy of Diaphragm and Pectoral Muscles in Critically Ill Patients. Anesthesiology. 2019 Sep;131(3):569-79.

(*) This study reports an ultrasound evaluation of thickness changes of the diaphragm and pectoral muscles in a large cohort of critically ill patients, with and without mechanical ventilation. It showed that ultrasound allows identification of specific early diaphragm atrophy affecting the majority of mechanically ventilated patients.

2. Goligher EC, Dres M, Fan E, Rubenfeld GD, Scales DC, Herridge MS, et al. Mechanical Ventilation-induced Diaphragm Atrophy Strongly Impacts Clinical Outcomes. Am J Respir Crit Care Med. 2018 Jan 15;197(2):204-13.

(**) First publication reporting a relationship between diaphragm atrophy and clinical outcomes in critically ill patients.

3. Dres M, Dubé B-P, Mayaux J, Delemazure J, Reuter D, Brochard L, et al. Coexistence and Impact of Limb Muscle and Diaphragm Weakness at Time of Liberation from Mechanical Ventilation in Medical Intensive Care Unit Patients. Am J Respir Crit Care Med. 2017 01;195(1):57-66.

4. Laveneziana P, Albuquerque A, Aliverti A, Babb T, Barreiro E, Dres M, et al. ERS statement on respiratory muscle testing at rest and during exercise. Eur Respir J. 2019;53(6).

(**) The most recent guidelines on respiratory muscle testing with a section specifically concerning critically ill patients.

5. Levine S, Nguyen T, Taylor N, Friscia ME, Budak MT, Rothenberg P, et al. Rapid disuse atrophy of diaphragm fibers in mechanically ventilated humans. N Engl J Med. 2008 Mar 27;358(13):1327-35.

6. Goligher EC, Brochard LJ, Reid WD, Fan E, Saarela O, Slutsky AS, et al. 
Diaphragmatic myotrauma: a mediator of prolonged ventilation and poor patient outcomes in acute respiratory failure. Lancet Respir Med. 2019;7(1):90-8.

(*) This is a mediation analysis developing the concept of myotrauma and supporting the hypothesis that myotrauma due to ventilator over-assistance and under-assistance partially contribute to the effects of mechanical ventilation on clinical outcomes.

7. Dres M, Goligher EC, Heunks LMA, Brochard LJ. Critical illness-associated diaphragm weakness. Intensive Care Med. 2017 Oct 1;43(10):1441-52.

8. Spadaro S, Grasso S, Dres M, Fogagnolo A, Dalla Corte F, Tamburini N, et al. Point of Care Ultrasound to Identify Diaphragmatic Dysfunction after Thoracic Surgery. Anesthesiology. 2019 Aug;131(2):266-78.

9. Moury P-H, Cuisinier A, Durand M, Bosson J-L, Chavanon O, Payen J-F, et al. Diaphragm thickening in cardiac surgery: a perioperative prospective ultrasound study. Ann Intensive Care. 2019 Apr 24;9(1):50.

10. Soilemezi E, Vasileiou M, Spyridonidou C, Tsagourias M, Matamis D. Understanding Patient-Ventilator Asynchrony Using Diaphragmatic Ultrasonography. Am J Respir Crit Care Med. 2019 Aug 15;200(4):e27-8.

(*) This is an illustrative report of the potential value of combined monitoring of breathing patterns and ultrasound signals to detect patient-ventilator asynchrony.

11. Vetrugno L, Guadagnin GM, Barbariol F, Langiano N, Zangrillo A, Bove T. Ultrasound Imaging for Diaphragm Dysfunction: A Narrative Literature Review. J Cardiothorac Vasc Anesth [Internet]. 2019 Jan [cited 2019 May 5]; Available from: https://linkinghub.elsevier.com/retrieve/pii/S1053077019300035

12. Johnson RW, Ng KWP, Dietz AR, Hartman ME, Baty JD, Hasan N, et al. Muscle atrophy in mechanically-ventilated critically ill children. PloS One. 2018;13(12):e0207720.

13. Ng KWP, Dietz AR, Johnson R, Shoykhet M, Zaidman CM. Reliability of bedside 
ultrasound of limb and diaphragm muscle thickness in critically ill children. Muscle Nerve. 2019;59(1):88-94.

14. Glau CL, Conlon TW, Himebauch AS, Yehya N, Weiss SL, Berg RA, et al. Progressive Diaphragm Atrophy in Pediatric Acute Respiratory Failure. Pediatr Crit Care Med J Soc Crit Care Med World Fed Pediatr Intensive Crit Care Soc. 2018;19(5):406-11.

15. Boussuges A, Gole Y, Blanc P. Diaphragmatic motion studied by m-mode ultrasonography: methods, reproducibility, and normal values. Chest. 2009 Feb;135(2):391400.

16. Spiesshoefer J, Henke C, Herkenrath SD, Randerath W, Brix T, Görlich D, et al. Noninvasive Prediction of Twitch Transdiaphragmatic Pressure: Insights from Spirometry, Diaphragm Ultrasound, and Phrenic Nerve Stimulation Studies. Respir Int Rev Thorac Dis. 2019 Aug 6;1-11.

17. Dres M, Demoule A. Diaphragm dysfunction during weaning from mechanical ventilation: an underestimated phenomenon with clinical implications. Crit Care. 2018 Mar 20;22(1):73.

(*) This review summarizes recent findings on the use of diaphragm ultrasound during the weaning process.

18. Guimarães-Costa R, Similowski T, Rivals I, Morélot-Panzini C, Nierat M-C, Bui MT, et al. Human diaphragm atrophy in amyotrophic lateral sclerosis is not predicted by routine respiratory measures. Eur Respir J. 2019 Feb;53(2).

(*) This study evaluated the correlation between diaphragm histological findings and pulmonary function tests.

19. Goligher EC, Laghi F, Detsky ME, Farias P, Murray A, Brace D, et al. Measuring diaphragm thickness with ultrasound in mechanically ventilated patients: feasibility, reproducibility and validity. Intensive Care Med. 2015 Apr;41(4):642-9. 
20. Dubé B-P, Dres M, Mayaux J, Demiri S, Similowski T, Demoule A. Ultrasound evaluation of diaphragm function in mechanically ventilated patients: comparison to phrenic stimulation and prognostic implications. Thorax. 2017 Sep;72(9):811-8.

21. Oppersma E, Hatam N, Doorduin J, van der Hoeven JG, Marx G, Goetzenich A, et al. Functional assessment of the diaphragm by speckle tracking ultrasound during inspiratory loading. J Appl Physiol (1985). 2017 May 18;jap.00095.2017.

22. Dres M, Goligher EC, Dubé B-P, Morawiec E, Dangers L, Reuter D, et al. Diaphragm function and weaning from mechanical ventilation: an ultrasound and phrenic nerve stimulation clinical study. Ann Intensive Care. 2018 Apr 23;8(1):53.

(*) This study compared the use of phrenic nerve stimulation and diaphragm ultrasound to predict weaning outcome.

23. Eltrabili HH, Hasanin AM, Soliman MS, Lotfy AM, Hamimy WI, Mukhtar AM. Evaluation of Diaphragmatic Ultrasound Indices as Predictors of Successful Liberation From Mechanical Ventilation in Subjects With Abdominal Sepsis. Respir Care. 2019 May;64(5):564-9.

24. Qing Q, Liang M, Sun Q, Xie B, Yang C, Liang W, et al. Using twitch tracheal airway pressure, negative inhale forced pressure, and Medical Research Council score to guide weaning from mechanical ventilation. J Thorac Dis. 2018 Jul;10(7):4424-32.

25. Rittayamai N, Hemvimon S, Chierakul N. The evolution of diaphragm activity and function determined by ultrasound during spontaneous breathing trials. J Crit Care. 2019 Jun;51:133-8.

26. Vivier E, Muller M, Putegnat J-B, Steyer J, Barrau S, Boissier F, et al. Inability of diaphragm ultrasound to predict extubation failure: a multicenter study. Chest. 2019 Jun;155(6):1131-1139.

(**) This study reported no difference in diaphragm thickening fraction according to the 
extubation outcome in patients who passed the spontaneous breathing trial. This finding suggests that the diaphragm is no longer involved in the weaning process once patients have passed the spontaneous breathing trial.

27. Spadaro S, Grasso S, Mauri T, Dalla Corte F, Alvisi V, Ragazzi R, et al. Can diaphragmatic ultrasonography performed during the T-tube trial predict weaning failure? The role of diaphragmatic rapid shallow breathing index. Crit Care 1. 2016 Sep 28;20(1):305.

28. Palkar A, Narasimhan M, Greenberg H, Singh K, Koenig S, Mayo P, et al. Diaphragm Excursion-Time Index: A New Parameter Using Ultrasonography to Predict Extubation Outcome. Chest. 2018 May;153(5):1213-20.

29. Marchioni A, Castaniere I, Tonelli R, Fantini R, Fontana M, Tabbì L, et al. Ultrasound-assessed diaphragmatic impairment is a predictor of outcomes in patients with acute exacerbation of chronic obstructive pulmonary disease undergoing noninvasive ventilation. Crit Care. 2018 Apr 27;22(1):109.

30. Chino K, Ohya T, Katayama K, Suzuki Y. Diaphragmatic shear modulus at various submaximal inspiratory mouth pressure levels. Respir Physiol Neurobiol. 2018 Mar 19;252253:52-7.

31. Frich LH, Lambertsen KL, Hjarbaek J, Dahl JS, Holsgaard-Larsen A. Musculoskeletal application and validation of speckle-tracking ultrasonography. BMC Musculoskelet Disord. 2019 May 4;20(1):192.

32. Bachasson D, Dres M, Niérat M-C, Gennisson J-L, Hogrel J-Y, Doorduin J, et al. Diaphragm shear modulus reflects transdiaphragmatic pressure during isovolumetric inspiratory efforts and ventilation against inspiratory loading. J Appl Physiol. 2019 Mar;126(3):699-707.

(*) If confirmed in critically ill patients, this study would propose a new method of diaphragm evaluation based on diaphragm stiffness during inspiration. 
33. Piquilloud L, Beloncle F, Richard J-CM, Mancebo J, Mercat A, Brochard L. Information conveyed by electrical diaphragmatic activity during unstressed, stressed and assisted spontaneous breathing: a physiological study. Ann Intensive Care. 2019 Aug $14 ; 9(1): 89$.

34. Bellani G, Bronco A, Arrigoni Marocco S, Pozzi M, Sala V, Eronia N, et al. Measurement of Diaphragmatic Electrical Activity by Surface Electromyography in Intubated Subjects and Its Relationship With Inspiratory Effort. Respir Care. 2018 Nov;63(11):1341-9. 35. Bellani G, Mauri T, Coppadoro A, Grasselli G, Patroniti N, Spadaro S, et al. Estimation of Patient's Inspiratory Effort From the Electrical Activity of the Diaphragm. Crit Care Med. 2013 Mar 8;

36. Essouri S, Baudin F, Mortamet G, Beck J, Jouvet P, Emeriaud G. Relationship Between Diaphragmatic Electrical Activity and Esophageal Pressure Monitoring in Children. Pediatr Crit Care Med. 2019 Jul;20(7):e319-25.

37. Jansen D, Jonkman AH, Roesthuis L, Gadgil S, van der Hoeven JG, Scheffer G-JJ, et al. Estimation of the diaphragm neuromuscular efficiency index in mechanically ventilated critically ill patients. Crit Care. 2018 27;22(1):238.

38. Dres M, Schmidt M, Ferre A, Mayaux J, Similowski T, Demoule A. Diaphragm electromyographic activity as a predictor of weaning failure. Intensive Care Med. 2012 Dec;38(12):2017-25.

39. Jonkman AH, Jansen D, Gadgil S, Keijzer C, Girbes ARJ, Scheffer G-J, et al. Monitoring patient-ventilator breath contribution in the critically ill during neurally adjusted ventilatory assist: reliability and improved algorithms for bedside use. J Appl Physiol (1985). 2019 Jul 1;127(1):264-71.

40. Grieco DL, Menga LS, Eleuteri D, Antonelli M. Patient self-inflicted lung injury: implications for acute hypoxemic respiratory failure and ARDS patients on non-invasive 
support. Minerva Anestesiol. 2019 Mar 12;

41. Schepens T, Goligher EC. Lung- and Diaphragm-protective Ventilation in Acute Respiratory Distress Syndrome: Rationale and Challenges. Anesthesiology. 2019 Apr;130(4):620-33.

42. Spadaro S, Karbing DS, Dalla Corte F, Mauri T, Moro F, Gioia A, et al. An open-loop, physiological model based decision support system can reduce pressure support while acting to preserve respiratory muscle function. J Crit Care. 2018 Dec;48:407-13. 
Figure 1. Panel A is a schematic representation of the diaphragm (in red) and phrenic nerves (black) in the chest wall. Panel B is an anatomic representation of the phrenic nerves across the mediastinum (Credit Robin Jacqueline).

Figure 2. Description of diaphragm ultrasound intercostal and subcostal windows.

Figure 3. Shear wave elastography on the right hemi-diaphragm via the intercostal approach. Note the increase in shear modulus (SMdi) $(+17.8 \mathrm{kPa})$ between end-expiration (left panel) and end-inspiration (right panel), illustrating the increase in diaphragm stiffness. 
Figure 1.

A

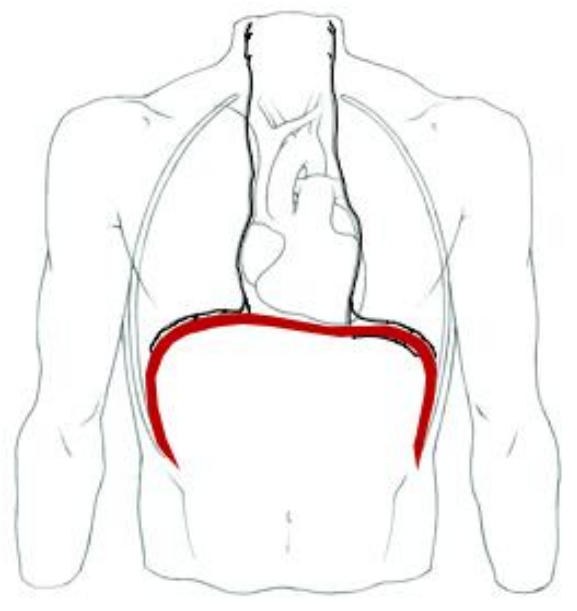

B

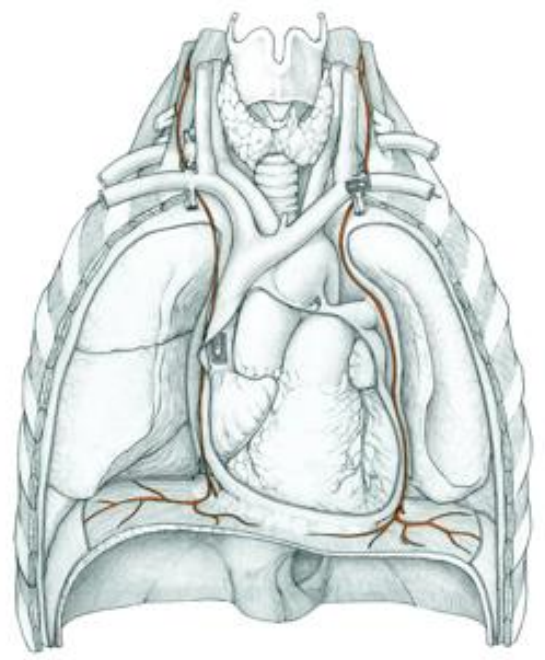


Figure 2.

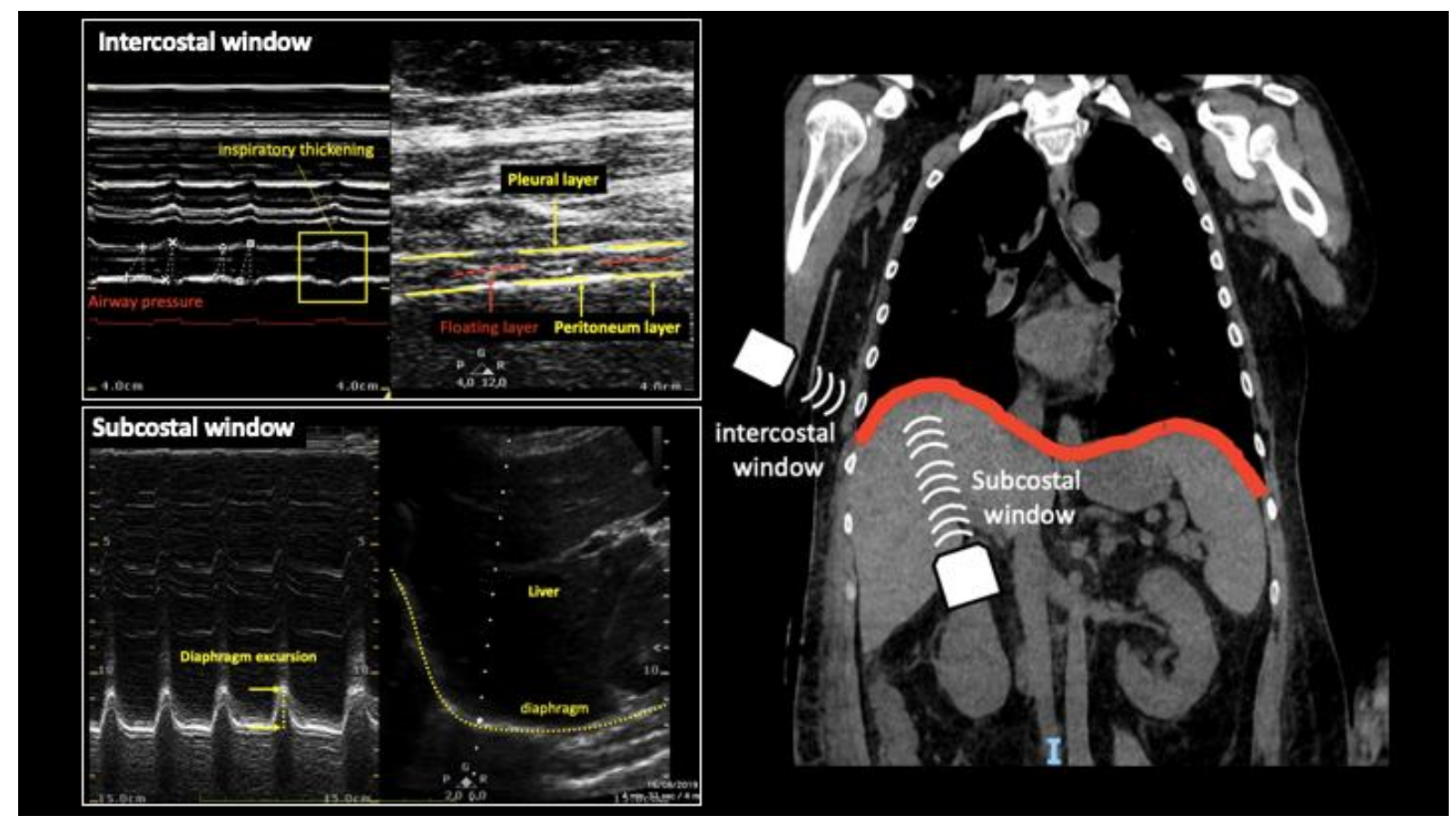


Figure 3.

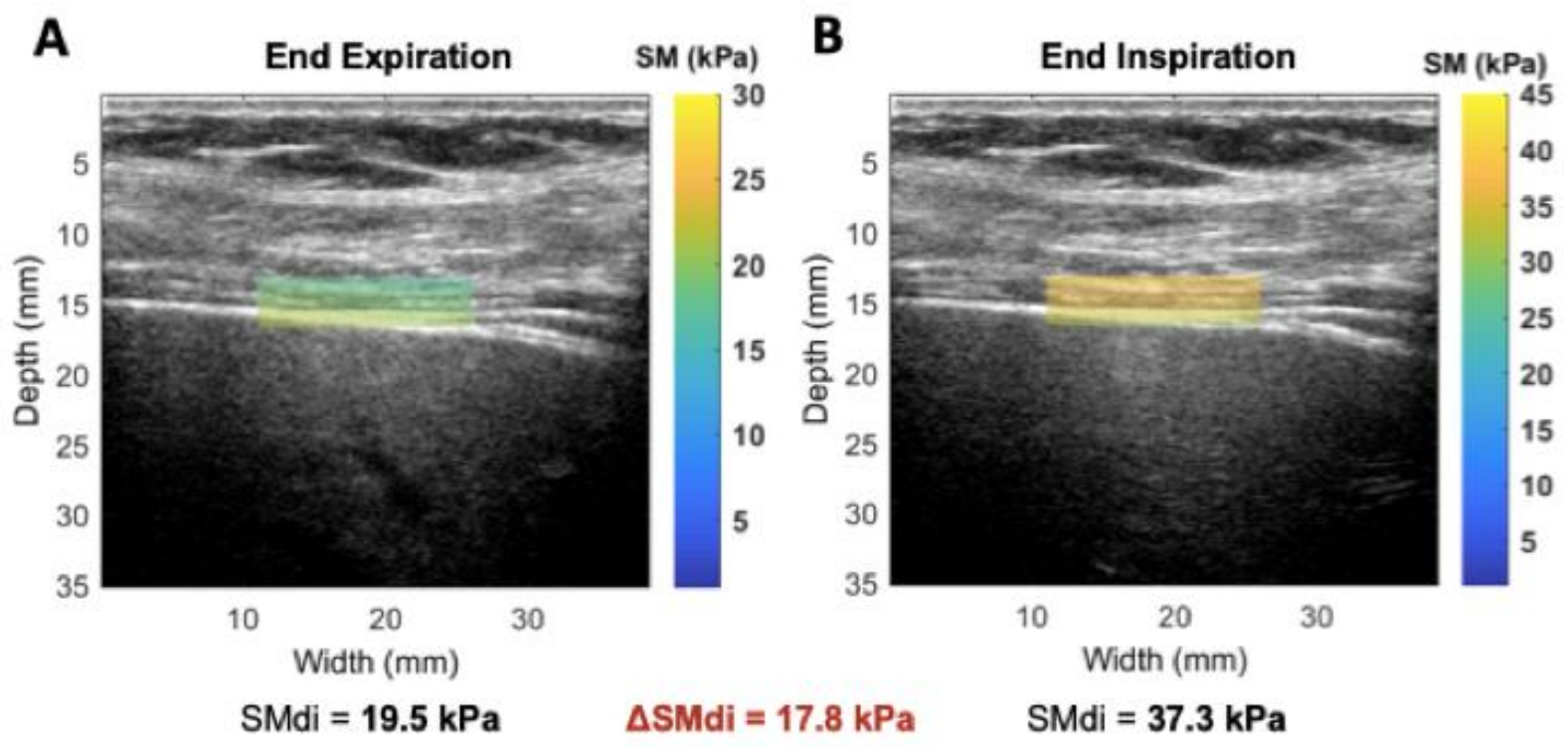


Table 1. Diaphragm function monitoring techniques

\begin{tabular}{|c|c|c|c|c|c|}
\hline & & Description & Advantages & Limitations & Normal values \\
\hline \multirow[t]{2}{*}{$\begin{array}{l}\text { Pressure- } \\
\text { generating } \\
\text { capacity }\end{array}$} & Pdi,max & $\begin{array}{l}\text { Absolute sum of Peso and Pga during } \\
\text { maximum inspiratory effort. }\end{array}$ & $\begin{array}{l}\text { Reference method for diaphragm } \\
\text { function outside the ICU }\end{array}$ & $\begin{array}{l}\text { Esophageal and gastric balloon } \\
\text { are required } \\
\text { Requires the patient's } \\
\text { cooperation }\end{array}$ & $\begin{array}{l}\text { Between } 100 \text { and } 150 \\
\mathrm{cmH}_{2} \mathrm{O}(4)\end{array}$ \\
\hline & Ptr,stim & $\begin{array}{l}\text { Tracheal pressure during supramaximal } \\
\text { magnetic phrenic nerve stimulation }\end{array}$ & $\begin{array}{l}\text { Reference method for diaphragm } \\
\text { function in the ICU }\end{array}$ & $\begin{array}{l}\text { Not widely available } \\
\text { Requires skills }\end{array}$ & $>-11 \mathrm{cmH}_{2} \mathrm{O}(7)$ \\
\hline \multirow[t]{2}{*}{ EMG } & Crural diaphragm & $\begin{array}{l}\text { Electrical signal obtained by a dedicated } \\
\text { esophageal catheter with multi-array } \\
\text { electrodes that capture the electrical activity } \\
\text { of the diaphragm. }\end{array}$ & $\begin{array}{l}\text { Continuous monitoring } \\
\text { Noninvasive } \\
\text { Correlated with Pdi }\end{array}$ & $\begin{array}{l}\text { High inter-patient variability } \\
\text { Not available on all ventilators }\end{array}$ & $\begin{array}{l}>10 \mu \text { Volts during } \\
\text { spontaneous breathing (33) }\end{array}$ \\
\hline & Surface EMG & $\begin{array}{l}\text { Electrical signal obtained by surface } \\
\text { electrodes placed on the skin. }\end{array}$ & $\begin{array}{l}\text { Noninvasive } \\
\text { Continuous monitoring }\end{array}$ & ECG contamination & No normal values \\
\hline \multirow{3}{*}{ Ultrasound } & Thickening fraction & $\begin{array}{l}\text { Intercostal approach between the } 8^{\text {th }} \text { and } \\
10^{\text {th }} \text { intercostal space. It is calculated as the } \\
\text { ratio of (Ti-Te)/Te and expressed as } \% \text {. }\end{array}$ & $\begin{array}{l}\text { Noninvasive } \\
\text { Correlated with Pdi }\end{array}$ & $\begin{array}{l}\text { Not continuous } \\
\text { Poor reproducibility } \\
\text { Difficult acquisition }\end{array}$ & $>20-25 \%$ in the ICU (22) \\
\hline & Excursion & $\begin{array}{l}\text { Subcostal approach through the liver } \\
\text { window. It is measured as the maximum } \\
\text { displacement of the right hemi-diaphragm } \\
\text { during the respiratory cycle. }\end{array}$ & $\begin{array}{l}\text { Noninvasive } \\
\text { Easy to measure }\end{array}$ & $\begin{array}{l}\text { Poor correlation with pressure- } \\
\text { generating capacity indices }\end{array}$ & $\begin{array}{l}\text { Women }>3.6 \mathrm{~cm} \\
\text { Men }>4.7 \mathrm{~cm} \\
\text { During maximum effort (15) }\end{array}$ \\
\hline & Combined indices & $\begin{array}{l}\text { - Diaphragm excursion time index (28) } \\
\text { - Diaphragmatic-RSBI (27) }\end{array}$ & $\begin{array}{l}\text { Combined evaluation of } \\
\text { diaphragm and breathing pattern }\end{array}$ & $\begin{array}{l}\text { More studies are needed to } \\
\text { confirm their usefulness }\end{array}$ & Not reported \\
\hline
\end{tabular}

Pdi, transdiaphragmatic pressure; Ptr,stim, change in tracheal pressure induced by magnetic phrenic nerve stimulation, Peso, esophageal pressure; Pga, gastric pressure; EMG, electromyogram; ICU, intensive care unit; ECG, electrocardiogram; Tins, inspiratory time; Ti, diaphragm inspiratory thickness; Te, diaphragm expiratory thickness. 